\title{
Identification of High Affinity Non-Peptidic Small Molecule Inhibitors of MDM2-p53 Interactions through Structure-Based Virtual Screening Strategies
}

\author{
Srinivas Bandaru ${ }^{1,2}$, Deepika Ponnala ${ }^{1}$, Chandana Lakkaraju ${ }^{1}$, Chaitanya Kumar \\ Bhukya $^{1}$, Uzma Shaheen ${ }^{1}$, Anuraj Nayarisseri ${ }^{3 *}$
}

\begin{abstract}
Background: Approaches in disruption of MDM2-p53 interactions have now emerged as an important therapeutic strategy in resurrecting wild type $\mathbf{p 3}$ functional status. The present study highlights virtual screening strategies in identification of high affinity small molecule non-peptidic inhibitors. Nutlin3A and RG7112 belonging to compound class of Cis-imidazoline, MI219 of Spiro-oxindole class and Benzodiazepine derived TDP 665759 served as query small molecules for similarity search with a threshold of $95 \%$. The query molecules and the similar molecules corresponding to each query were docked at the transactivation binding cleft of MDM2 protein. Aided by MolDock algorithm, high affinity compound against MDM2 was retrieved. Patch Dock supervised Protein-Protein interactions were established between MDM2 and ligand (query and similar) bound and free states of p53. Compounds with PubCid 68870345, 77819398, 71132874, and 11952782 respectively structurally similar to Nutlin3A, RG7112, Mi219 and TDP 665759 demonstrated higher affinity to MDM2 in comparison to their parent compounds. Evident from the protein-protein interaction studies, all the similar compounds except for 77819398 (similar to RG 7112) showed appreciable inhibitory potential. Of particular relevance, compound 68870345 akin to Nutlin $3 \mathrm{~A}$ had highest inhibitory potential that respectively showed $1.3,1.2,1.16$ and 1.26 folds higher inhibitory potential than Nutilin 3A, MI 219, RG 7112 and TDP 1665759. Compound 68870345 was further mapped for structure based pharamacophoric features. In the study, we report Cis-imidazoline derivative compound; Pubcid: 68870345 to have highest inhibitory potential in blocking MDM2-p53 interactions hitherto discovered.
\end{abstract}

Keywords: MDM2-p53 interactions - virtual screening - molecular docking

Asian Pac J Cancer Prev, 16 (9), 3759-3765

\section{Introduction}

Since the discovery of p53 in 1979 (Lane et al., 1979; DeLeo et al., 1979; Linzer et al., 1979); it has surfaced as a most important tumor suppressor protein central to regulation of cell cycle, apoptosis, DNA repair, senescence, and angiogenesis (Vousden et al., 2002; Fridman et al., 2003; Teodor et al., 2007). The prominent role of p53 is reflected in nearly $50 \%$ cases of malignancies wherein p53 gene is either mutated or under expressed (Feki et al., 2004, Srivatanakul et al., 2004; Xu et al., 2012, Tian et al., 2013). However, the pioneering studies by Oliner et al. (1992) provided a convincing evidence of involvement of other regulatory proteins that encourages abnormal cell division. Involvement of MDM2 (Murine Double Minute 2) as an ancillary protein in sarcomas (Oliner et al., 1992, Yang et al., 2014) provided a fresh avenues in oncological research which offered a clue in understanding the pathophysiological rationale behind the cancers wherein wild type status of p53 was retained.

MDM2 gene is known to be transcribed by p53 itself (Momand et al., 1992; Jun Liu et al, 2011), once expressed, MDM 2 binds to the p53 transactivation domain and inhibits its transcriptional activity (Momand et al., 1992; Chen et al., 1993) and exports p53 out of the nucleus. The event is followed by proteasome-mediated degradation of p53 that makes it degradation and rendering it inaccessible to the target genes (Freedman et al., 1998; Haupt et al., 1997). The process can be thought of feedback loop mechanism wherein both p53 and MDM2 is maintained in the basal levels in the normal cell (Wu et al., 1993). However, in certain malignancies the over expression of MDM2 renders p53 inactive which involves synergistic MDM2-p53 interactions (Momand et al., 1998).

${ }^{1}$ Institute of Genetics and Hospital for Genetic Diseases, Osmania University, ${ }^{2}$ National Institute of Pharmaceutical Education and Research, Hyderabad, ${ }^{3}$ In silico Research Laboratory, Eminent Biosciences, Indore, India *For correspondence: anuraj@ eminentbio.com 
Approaches in disruption of MDM2-p53 interactions have now surfaced as an important therapeutic strategy in resurrection of p53 function. Highly potent and specific small-molecule inhibitors with desirable pharmaceutical properties to inhibit MDM2-p53 interactions such as Nutlin-3 (Vassilev et al., 2004) and MI-219 (Shangary et al., 2008) are now available. Studies using these inhibitors in preclinical models have already provided strong evidence that targeting the MDM2-p53 interaction using small-molecule inhibitors is a promising cancer therapeutic approach (Vassilev et al., 2004; Patton et al., 2006; Tovar et al., 2006; Sarek et al., 2007). Nevertheless, as every drug suffers setbacks, Nutlin-3 and MI-219 in spite being potential inhibitors haves hown limited tumor volume reduction (Ray et al., 2012, Stakleff et al., 2012). Therefore in the view of above, through virtual screening approaches, we sought to identify a novel compound as a substitute to the customary drugs anticipated having higher affinity against MDM2 protein and possibly having commendable potential in disrupting MDM-p53 interactions.

\section{Materials and Methods}

Selection of inhibitors and structure similarity search

Nutlin3A and RG7112 belonging to compound class of cis-imidazoline, MI219 of spiro-oxindole class and benzodiazepine derived TDP 665759 served as query molecules for shape similarity search.

Structure similarity search was performed by NCBI's Pubchem search with a threshold of 95\%. All the similar molecules were screened with Lipinski filters.

\section{Ligand receptor docking}

Molecular docking program Molegro Virtual Docker (MVD, 2010.4.0.0) which includes highly efficient PLP (Chanda Sinha et al., 2015) and MolDock scoring function (Yang et al., 2004) provided flexible platform for molecular docking (Bandaru et al., 2014). The optimized structures of Nutilin3A, MI-69, MI-217, RG7112 and TDP 7115 were docked into the p53 binding cleft of MDM2 protein. Docking parameters were set to 0.20 $\AA$ as grid resolution, maximum iteration of 1500 and maximum population size of 50. Energy minimization and hydrogen bonds were optimized after the docking. Simplex evolution was set at maximum steps of 300 with neighborhood distance factor of 1 . Binding affinity and interactions of inhibitor with protein was evaluated on the basis of the internal ES (Electrostatic Interaction), internal hydrogen bond interactions and sp2-sp2 torsions. Post docked ligand-receptor complex energy was minimized using Nelder Mead Simplex Minimization (using non-grid force field and $\mathrm{H}$ bond directionality) (Nelder et al., 1965).

\section{Protein-protein docking studies}

Structure of the MDM2 oncoprotein bound to the p53 tumor suppressor transactivation domain was retrieved from Protein Databank with (PDB accession number: 1YCR). Protein - Protein docking was executed through object recognition and image segmentation algorithm embedded in Patchdock server (Schneidman et al., 2005). Default parameter was set as clustering RMSD at 4.0.

\section{Lipinksi filters toxicity screening and bioactivity prediction of compounds}

All the similar compounds retrieved were screened for its drug ability by lipinksi filters. The toxicity screening was achieved by using LAZAR toxicity prediction server (Maunz et al., 2013). Biological activity score of the ligands was predicted using Molinspiration webserver ( ${ }^{\circ}$ Molinspiration Cheminformatics, 2014). LC 50 was predicted using T.E.S.T. Version 4.1 (2012, U.S. Environmental Protection Agency) software. The complete ADMET properties was calculated using admetSAR (Cheng et al., 2012).

\section{Solvent accessible surface area (SASA) and interface property calculation}

Solvent accessible surface area of the complexes were calculated by GETAREA server (Ahmad et al., 2004), protein interfaces calculated by Aquaprot (Reichmann et al., 2008) and interface property was calculated using 2P2I inspector (Basse et al., 2013) online server.

\section{Results and Discussion}

Evident from rerank scores, all the akin compounds identified against parent compound had higher binding affinity against MDM2 protein in comparison to parent compounds. Further, compound PubCid: 71132874 akin to MI 219 showed highest affinity against the MDM2 receptor amongst the compounds undertaken in this study. The docking scores of top selected compounds belonging to each lead compound are provided in Table 1.

The compounds were further screened for their in silico ADMET profile, compound PubCid: 11952782

Table 1. MolDock Algorithm Aided Docking of Compounds in p53 Transactivation Binding Cleft of MDM2 Protein. PubCid: 71132874 Akin to MI 219 Showed Highest Affinity Against the MDM2 Receptor

\begin{tabular}{|c|c|c|c|c|}
\hline Compound & MolDock Score & Rerank Score & Internal & H Bond \\
\hline MI219 & -135.95 & -72.1997 & -29.8749 & -2.45121 \\
\hline TDP 665759 & -113.4 & -71.5204 & 4.99076 & 0 \\
\hline RG7112 & -117.551 & -61.9914 & 2.64802 & -1.37174 \\
\hline NUTLIN 3A & -109.209 & -61.9045 & -9.8754 & -1.0106 \\
\hline PubCid: 71132874 (MI 219 SIMILAR) & -165.95 & -106.647 & -26.9939 & -2.63359 \\
\hline PubCid: 77819398 (RG 7112 SIMILAR) & -164.829 & -104.109 & 2.92253 & -2.5 \\
\hline PubCid: 11952782 (TDP 665759 SIMILAR) & -123.099 & -84.7467 & 39 & 0 \\
\hline PubCid: 68870345 (NUTLIN SIMILAR ) & -275.21 & -99.681 & 5.2 & -2.34 \\
\hline
\end{tabular}


High Affinity Non-Peptidic Small Molecule Inhibitors of MDM2-p53 - Interaction through Virtual Screening Strategies akin to TDP 665759 and compound 77819398 akin to RG 7112 showed toxicity being mutagenic and carcinogenic respectively. The ADMET profile of the compounds is represented in Table 2.

As evident from protein-protein docking studies, the MDM2-p53 interactions are efficiently inhibited in presence of inhibitors as compared to ligand free MDM2, thus implying there occurs a declined MDM2-p53 interactions in presence of inhibitors. It is interesting to note that, except for compound PubCid:77819398 akin to

Table 2a.ADMET Prediction of Virtually Screened Compounds by ADMETSAR Server. Additionally Toxicity was Calculated by LAZAR Toxicity Prediction Server. Compound PubCID 68870345 and 71132874 respectively Similar to Nutlin 3A and MI 219 were Predicted to be Safe. Compound (PubCID 11952782) akin to TDP 7115 was mutagenic while Compound (PubCid: 77819398) akin to RG7112 was Predicted to be a Carcinogen

\begin{tabular}{|c|c|c|c|c|}
\hline \multirow[b]{2}{*}{ Model } & \multicolumn{2}{|c|}{$\begin{array}{l}\text { PubCid: } 71132874 \\
\text { (MI } 219 \text { SIMILAR) }\end{array}$} & \multicolumn{2}{|c|}{$\begin{array}{l}\text { PubCid: } 77819398 \\
\text { (RG } 7112 \text { SIMILAR) }\end{array}$} \\
\hline & Result & $\overline{\text { Probability }}$ & Result & Probability \\
\hline \multicolumn{5}{|l|}{ Absorption } \\
\hline Blood-Brain Barrier & BBB- & 0.547 & $\mathrm{BBB}+$ & 0.7325 \\
\hline Human Intestinal Absorption & HIA+ & 1 & HIA+ & 1 \\
\hline Caco-2 Permeability & Caco2- & 0.6511 & Caco2- & 0.5494 \\
\hline P-glycoprotein Substrate & Substrate & 0.9166 & Substrate & 0.8089 \\
\hline P-glycoprotein Inhibitor & Non-inhibitor & 0.5104 & Non-inhibitor & 0.5604 \\
\hline Renal Organic Cation Transporter & Non-inhibitor & 0.8754 & Non-inhibitor & 0.5437 \\
\hline \multicolumn{5}{|l|}{ Distribution \& Metabolism } \\
\hline CYP450 2C9 Substrate & Non-substrate & 0.803 & Non-substrate & 0.6844 \\
\hline CYP450 2D6 Substrate & Non-substrate & 0.7822 & Non-substrate & 0.7846 \\
\hline CYP450 3A4 Substrate & Substrate & 0.7543 & Substrate & 0.7369 \\
\hline CYP450 1A2 Inhibitor & Non-inhibitor & 0.7047 & Non-inhibitor & 0.7395 \\
\hline CYP450 2C9 Inhibitor & Non-inhibitor & 0.592 & Non-inhibitor & 0.57 \\
\hline CYP450 2D6 Inhibitor & Non-inhibitor & 0.7918 & Non-inhibitor & 0.8051 \\
\hline CYP450 2C19 Inhibitor & Non-inhibitor & 0.5183 & Non-inhibitor & 0.5664 \\
\hline CYP450 3A4 Inhibitor & Inhibitor & 0.9146 & Inhibitor & 0.6919 \\
\hline CYP Inhibitory Promiscuity & Low & 0.6003 & Low & 0.6134 \\
\hline \multicolumn{5}{|l|}{ Excretion \& Toxicity } \\
\hline Human Ether-a-go-go-Related Gene Inhibition & Weak inhibitor & 0.9026 & Weak inhibitor & 0.6894 \\
\hline AMES Toxicity & Non toxic & 0.6328 & Non toxic & 0.563 \\
\hline Fish Toxicity & High FHMT & 0.9989 & High FHMT & 0.9868 \\
\hline Acute Oral Toxicity & III & 0.6288 & III & 0.5731 \\
\hline \multirow[t]{3}{*}{ HoneyBee toxicity } & Low & 0.8123 & Low & 0.7411 \\
\hline & \multicolumn{2}{|c|}{$\begin{array}{c}\text { PubCid: } 11952782 \\
\text { (TDP 665759 SIMILAR) }\end{array}$} & \multicolumn{2}{|c|}{$\begin{array}{c}\text { PubCid: } 68870345 \\
\text { (NUTLIN SIMILAR ) }\end{array}$} \\
\hline & Result & Probability & Result & Probability \\
\hline \multicolumn{5}{|l|}{ Absorption } \\
\hline Blood-Brain Barrier & $\mathrm{BBB}+$ & 0.9635 & $\mathrm{BBB}+$ & 0.7745 \\
\hline Human Intestinal Absorption & $\mathrm{HIA}+$ & 0.9861 & HIA+ & 1 \\
\hline Caco-2 Permeability & Caco2- & 0.5428 & Caco2- & 0.5082 \\
\hline P-glycoprotein Substrate & Substrate & 0.7175 & Substrate & 0.7877 \\
\hline P-glycoprotein Inhibitor & Non-inhibitor & 0.7525 & Inhibitor & 0.5522 \\
\hline Renal Organic Cation Transporter & Non-inhibitor & 0.6984 & Non-inhibitor & 0.52 \\
\hline \multicolumn{5}{|l|}{ Distribution \& Metabolism } \\
\hline CYP450 2C9 Substrate & Non-substrate & 0.8062 & Non-substrate & 0.7524 \\
\hline CYP450 2D6 Substrate & Non-substrate & 0.7567 & Non-substrate & 0.8536 \\
\hline CYP450 3A4 Substrate & Substrate & 0.6762 & Substrate & 0.6647 \\
\hline CYP450 1A2 Inhibitor & Non-inhibitor & 0.596 & Non-inhibitor & 0.8176 \\
\hline CYP450 2C9 Inhibitor & Non-inhibitor & 0.6678 & Non-inhibitor & 0.5564 \\
\hline CYP450 2D6 Inhibitor & Non-inhibitor & 0.8903 & Non-inhibitor & 0.8724 \\
\hline CYP450 2C19 Inhibitor & Inhibitor & 0.5692 & Non-inhibitor & 0.6094 \\
\hline CYP450 3A4 Inhibitor & Inhibitor & 0.8028 & Inhibitor & 0.7239 \\
\hline CYP Inhibitory Promiscuity & Low & 0.508 & Low & 0.6664 \\
\hline \multicolumn{5}{|l|}{ Excretion \& Toxicity } \\
\hline Human Ether-a-go-go-Related Gene Inhibition & Weak inhibitor & 0.8601 & Weak inhibitor & 0.5113 \\
\hline AMES Toxicity & Non toxic & 0.594 & Non toxic & 0.6423 \\
\hline Fish Toxicity & High FHMT & 0.9785 & High FHMT & 0.9161 \\
\hline Acute Oral Toxicity & III & 0.6793 & III & 0.6601 \\
\hline HoneyBee toxicity & Low & 0.9301 & Low & 0.8658 \\
\hline
\end{tabular}


Srinivas Bandaru et al

Table 2b. ADMET prediction of virtually screened compounds by ADMETSAR server. Additionally toxicity was calculated by LAZAR toxicity prediction server. Compound PubCID 68870345 and 71132874 respectively similar to Nutlin 3A and MI 219 were predicted to be safe. Compound (PubCID 11952782) akin to TDP 7115 was mutagenic while compound (PubCid: 77819398 ) akin to RG7112 was predicted to be a carcinogen.

\begin{tabular}{|c|c|c|c|c|c|}
\hline Compound & $\begin{array}{c}\text { DSSTox } \\
\text { Carcinogenic } \\
\text { Potency DBS } \\
\text { MultiCellCall }\end{array}$ & $\begin{array}{c}\text { DSSTox } \\
\text { Carcinogenic } \\
\text { Potency DBS } \\
\text { Mutagenicity }\end{array}$ & $\begin{array}{c}\text { DSSTox } \\
\text { Carcinogenic } \\
\text { Potency DBS } \\
\text { Rat }\end{array}$ & $\begin{array}{c}\text { DSSTox } \\
\text { Carcinogenic } \\
\text { Potency DBS } \\
\text { Hamster }\end{array}$ & $\begin{array}{c}\text { DSSTox } \\
\text { Carcinogenic } \\
\text { Potency DBS } \\
\text { Mouse }\end{array}$ \\
\hline $\begin{array}{l}\text { PubCid: 68870345 } \\
\text { (NUTLIN 3A SIMILAR) }\end{array}$ & non-carcinogen & non- mutagenic & non-carcinogen & non-carcinogen & non-carcinogen \\
\hline $\begin{array}{l}\text { PubCid: } 71132874 \\
\text { (MI 219 SIMILAR) }\end{array}$ & non-carcinogen & non- mutagenic & non-carcinogen & non-carcinogen & non-carcinogen \\
\hline $\begin{array}{l}\text { PubCid: } 11952782 \\
\text { (TDP } 665759 \text { SIMILAR) }\end{array}$ & non-carcinogen & mutagenic & non-carcinogen & non-carcinogen & non-carcinogen \\
\hline $\begin{array}{l}\text { PubCid: } 77819398 \\
\text { (RG } 7112 \text { SIMILAR) }\end{array}$ & non-carcinogen & non- mutagenic & non-carcinogen & carcinogen & non-carcinogen \\
\hline
\end{tabular}

Table 3. MDM2 and p53 protein docking scores evaluated by surface patch matching (Patch Dock Server)

\begin{tabular}{|c|c|c|c|}
\hline PROTEIN 1 & PROTEIN 2 & Score & Transformation \\
\hline MDM2 bound to : & z & & \\
\hline PubCid: 68870345 (NUTLIN SIMILAR ) & $\sum$ & 5490 & $-0.36-0.56-3.1140 .78-50.8211 .99$ \\
\hline PubCid: 71132874 (MI 219 SIMILAR) & ○̆ & 5560 & $3.13-0.72-1.54-4.20-5.684 .29$ \\
\hline PubCid: 11952782 (TDP 665759 SIMILAR) & $\bar{z}$ & 5842 & $1.350 .45-1.098 .770 .921 .44$ \\
\hline Mi 219 & 定 & 5914 & $-0.52-1.20-1.6843 .65-12.3521 .52$ \\
\hline NUTLIN 3A & 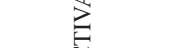 & 6290 & $-0.18-1.142 .6123 .66-54.5512 .43$ \\
\hline RG7112 & 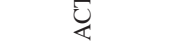 & 6394 & $-2.79-0.162 .4551 .31-25.60-15.44$ \\
\hline PubCid: 71132874 (MI 219 SIMILAR) & $\tilde{z}$ & 6394 & $(-3.11-0.64-1.18-5.16-16.32-3.05)$ \\
\hline TDP665759 & 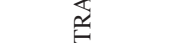 & 6926 & $2.430 .752 .8860 .62-11.85-21.74$ \\
\hline MDM2 UNBOUND & $\approx$ & 10134 & $-2.400 .251 .9442 .18-50.34-37.45$ \\
\hline
\end{tabular}

Table 4. Interface property calculations in ligand free and ligand bound states of MDM2-p53 Complex

\begin{tabular}{|c|c|c|c|c|c|c|}
\hline & $\begin{array}{c}\text { Total Interface } \\
\text { Area (A2) }\end{array}$ & $\begin{array}{c}\text { Gap } \\
\text { volume (A3) }\end{array}$ & $\begin{array}{c}\text { Gap } \\
\text { Index }\end{array}$ & SASA & $\begin{array}{l}\text { Buried } \\
\text { atoms }\end{array}$ & $\begin{array}{c}\text { Surface } \\
\text { atoms }\end{array}$ \\
\hline MDM2 UNBOUND STATE & 1481.8 & 783 & 0.52841 & 5794 & 652 & 758 \\
\hline \multicolumn{7}{|l|}{ MDM2 BOUND TO: } \\
\hline MI 219 & 628.7 & 1242.6 & 1.97646 & 6005 & 335 & 483 \\
\hline NUTLIN 3A & 698.2 & 1210 & 1.73303 & 5930 & 353 & 465 \\
\hline RG 7112 & 722.2 & 1121.6 & 1.55303 & 5970 & 330 & 488 \\
\hline TDP 665759 & 1340.6 & 721.2 & 0.53797 & 5823 & 340 & 478 \\
\hline PubCid: 77819398 (RG7112 SIMILAR) & 852.4 & 1009.6 & 1.18442 & 5797 & 336 & 482 \\
\hline PubCid: 11952782 (TDP 665759 SIMILAR) & 521 & 1421.2 & 2.72783 & 6005 & 335 & 483 \\
\hline PubCid: 71132874 (MI 219 SIMILAR) & 410.1 & 1655.2 & 4.03609 & 6040 & 336 & 482 \\
\hline PubCid: 68870345 (NUTILIN 3A SIMILAR) & 322.2 & 1828.7 & 5.67567 & 8582 & 328 & 490 \\
\hline
\end{tabular}

Table 5. Predicted LC 50 and bioactivity of compounds

\begin{tabular}{|c|c|c|c|c|c|c|c|}
\hline BIOACTIVITY & $\begin{array}{c}\text { LC } 5096 \\
\text { hour }\end{array}$ & $\begin{array}{l}\text { GPCR } \\
\text { ligand }\end{array}$ & $\begin{array}{c}\text { Ion channel } \\
\text { modulator }\end{array}$ & $\begin{array}{l}\text { Kinase } \\
\text { inhibitor }\end{array}$ & $\begin{array}{c}\text { Nuclear } \\
\text { receptor ligand }\end{array}$ & $\begin{array}{l}\text { Protease } \\
\text { inhibitor }\end{array}$ & $\begin{array}{l}\text { Enzyme } \\
\text { inhibitor }\end{array}$ \\
\hline $\begin{array}{l}\text { PubCid: } 71132874 \\
\text { MI } 219 \text { similar }\end{array}$ & 26.36 & 0.24 & -0.14 & -0.03 & -0.04 & 0.19 & 0 \\
\hline $\begin{array}{l}\text { PubCid: } 77819398 \\
\text { RG } 7112 \text { similar }\end{array}$ & 22.28 & -0.51 & -1.44 & -1.04 & -1 & -0.19 & -1.01 \\
\hline PubCid: 11952782 , TDP 665759 similar & 14.55 & 0.05 & -0.28 & -0.19 & -0.21 & -0.12 & -0.2 \\
\hline PubCid: 68870345 NUTLIN 3A similar & 12.24 & 0.03 & -0.56 & -0.14 & 0.04 & 0.07 & -0.24 \\
\hline
\end{tabular}

RG7112 all the similar compounds had superior inhibitory potential than their parent compounds. In particular compound with PubCid: 68870345 akin to Nutlin 3A had highest inhibitory potential among all the compounds (parent and their respective similar). PubCid: 68870345 showed showed 1.14 folds better inhibitory potential than its parent compounds Nutlin 3A. The patch dock scores (protein-protein docking scores) of MDM2-p53 interaction in presence of inhibitors and their respective akin is shown in Table 3. 
The MDM2-p53 docking results were further complemented by interface property calculations. Interface properties of MDM2-p53 complex in presence and absence of inhibitors is shown in Table 4. From extensive interface properties calculated it is quite apparent that all the similar compounds had well inhibitory potential than their respective parent compound. As mentioned afore, PubCid :68870345-a Nutlin 3A akin compound was superior among the undertaken compounds in preventing the MDM-p53 interactions (as revealed from patch dock scores),the interface properties calculations further asserts this observation. The concurrence between patch dock results and MDM2-P53 interface property calculation is supported by the fact that the total interface area in MDM-p53 complex was 2.1 folds declined in

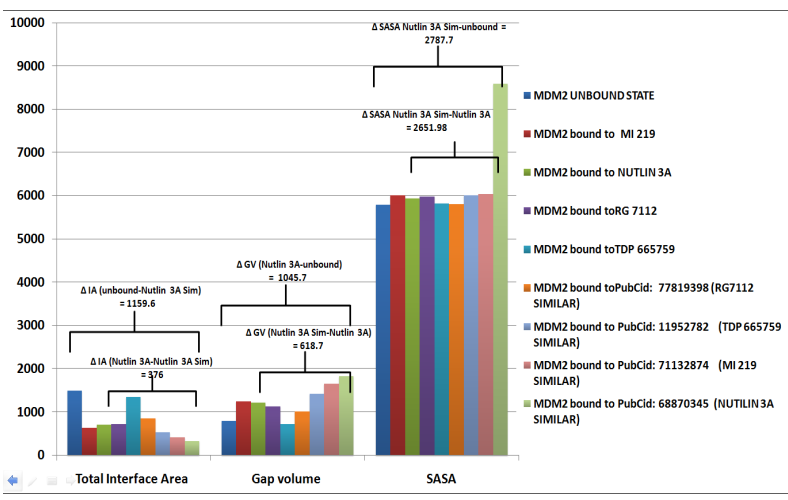

Figure 1. The Potential of Compounds in Blocking the MDM-p53 Interaction Followed the Descending Order of $68870345>71132874>11952782>\mathrm{Mi} 219$ $>$ Nutlin 3A > RG7112 > 77819398 > TDP 665759 > MDM2 Unbound. Evident form extensive interface analysis; Nutlin 3A similar compound had highest inhibitory potential in the present study. There was 1.44 folds increase in the SASA when MDM bound to Nutlin 3A similar to Nutlin 3A bound counterparts ( $\triangle$ SASA Nutlin 3A sim-Nutlin 3A=2651.98, folds $=1.44$ ). In addition, there was considerable decrease of interface area in the interactions involving Nutlin $3 \mathrm{~A}$ similar $(\triangle \mathrm{IA}$ Nutlin 3A-Nutlin 3ASim=376, folds=2.16). Further gap volumes testifies the inhibitory potential of Nutlin $3 \mathrm{~A}$ Similar than any other compound undertaken in the study ( $\Delta$ GVNutlin 3A Sim-Nutlin 3A=618.7, folds=1.51)

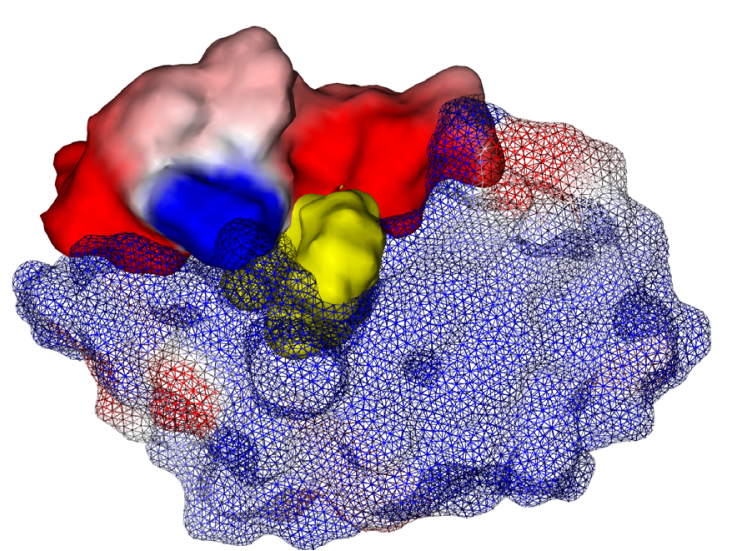

Figure 2. Electrostatic Surfaces of MDM2 (Solid) and p53 (mesh) in MDM2-p53 Complex. Compound PubCid: 68870345 Nutlin 3A similar (solid yellow) is bound between the interfaces presence of compound PubCid : 68870345 compared to the complex harboring its parent compound Nutlin 3A.Further the comparative analysis of the number of surface and buried atoms of the MDM2 -p53 complexes has unveiled that PubCid:68870345bound MDM2 -p53 complex had considerable increase in the number of surface atoms and a decrease in buried atoms implying a weak interaction between p53 and MDM2. Likewise, gap index and SASA was highest between MDM2-p53 in presence of PubCid :68870345 indicating it to be the powerful and potential inhibitor undertaken in the existing study. In addition to the analyses, the LC 50 values and bioactiity of the compounds were predicted. The LC 50 values at 96 hour interval were predicted to be least lethal (Table 5). In addition the similar compounds identified against their parents show enhanced bioactivity providing a clue for target specificity.

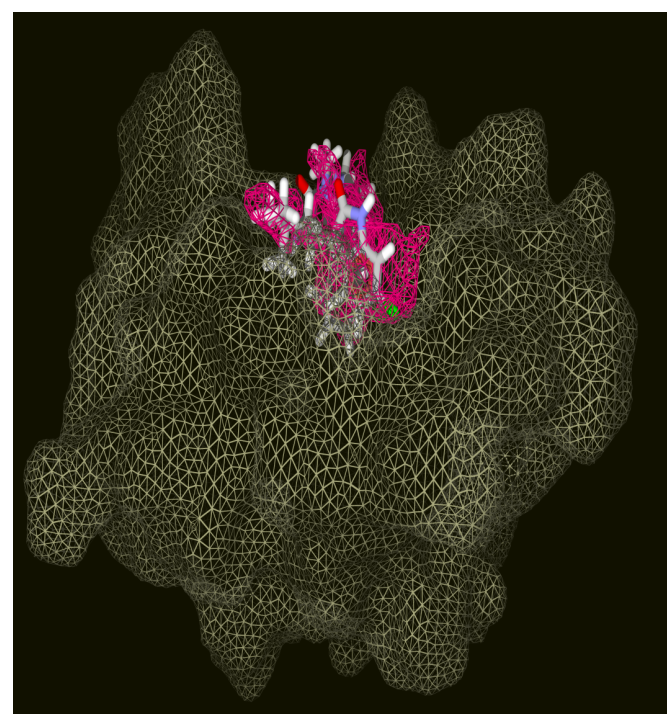

Figure 3. Compound PubCid 68870345 (Stick Model) Bound at the p53 Transactivation Domain Binding Site (Pink Mesh) in MDM2 Protin. The prior occupied high affinity inhibitor at the binding site of $\mathrm{p} 53$ transactivation domain in MDM2 falls short to interact with the p53 transactivation domain, thereby detains MDM2-p53 interactions
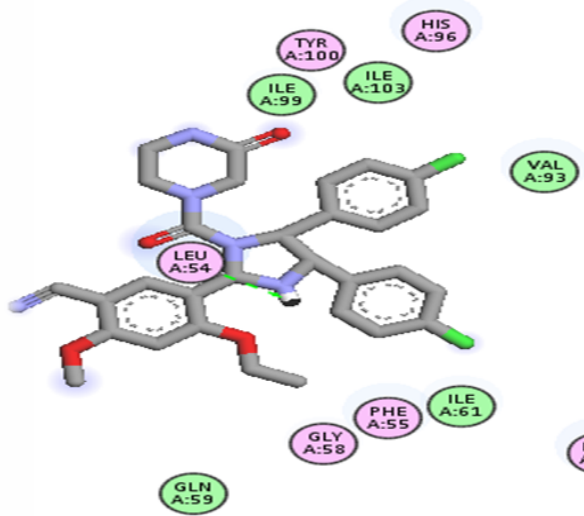

Figure 4. Interactions of Nutlin 3A Similar Compound PubCid 68870345 with MDM2. Residues circled in green participate in vanderwaals interaction while residues in pink forms electrostatic interactions. Hydrogen bonds are shown as green arrows 


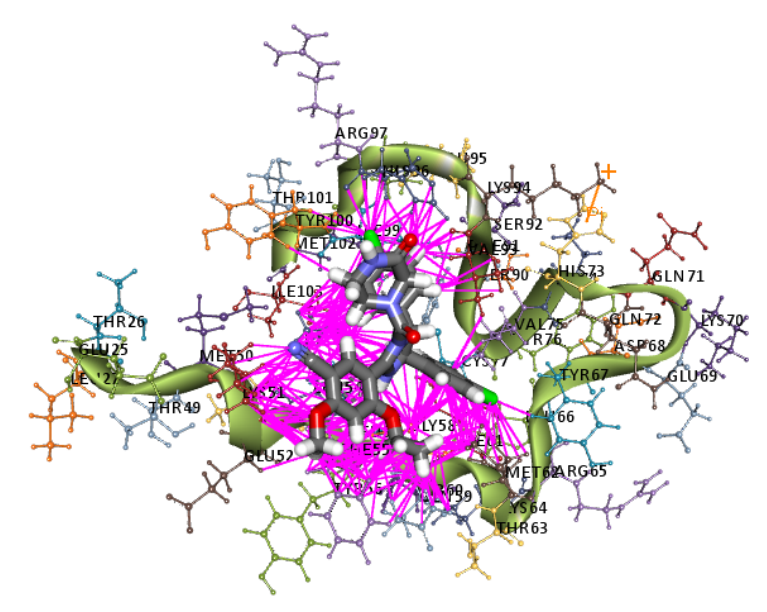

Figure 5. Binding Pattern of Compound PubCid 68870345 with MDM2. The pink lines represent various interactions like electrostatic, van der Waals, stearic, hydrogen bonding and hydrophobic interactions that enable energetically favourable binding of the ligand in the cavity

Solvent accessible surface area of the MDM2 -p53 complex in the presence of the parent and respective akin with that of the ligand free MDM2-P53 complex, Nutlin 3A akin bound MDM2-P53 complex showed highest total solvent accessibility surface area which gives a clue towards decreased MDM2 -P53 interaction. It is also imperative to note that the total solvent accessibility surface area of Nutlin 3A akin bound MDM2-P53 complex has increased by 1.45 folds when compared to the Nutlin3A bound MDM2-P53 complex.

Owing to superior inhibitory potential of Nutlin $3 \mathrm{~A}$ PubCid: 68870345 similar it was further mapped for its pharmacophoric properties. Figure 3 shows compound PubCid: 68870345 bound in p53 binding cleft of MDM2. In the cleft compound 68870345 shows van der waals interaction with Ile 61, 99 and 103, Val 75 and 93, Tyr 67 and Gln 59 and electrostatic interactions with leu 54, Tyr 100, His 96, Phe 55, Met 62 and Gly 58 while residues Leu 54 acts as hydrogen bond donor (Figure 4). The ligand binding pattern is shown in figure 5 .

In conclusion, the together with molecular docking analysis, protein-protein patch docking, interface property and SASA analysis has put forth that the Nutlin $3 \mathrm{~A}$ akin compound demonstrated and brought about the weakest interaction between MDM2 and p53, thereby making p53 available for carrying out its tumor suppressing actions in the cells.

MDM2 and p53 interaction is a primary mechanism for inhibition of the p53 function in cancers retaining wildtype p53, targeting the MDM2-p53 interaction by small molecules to reactivate p53 has emerged as a promising new cancer therapeutic strategy. In the present study the potential of Cis-imidazoline derivative (CID 68870345) - a compound akin to Nutlin 3A had appreciable potential to inhibit MDM2-p53 interactions than any compound in the study. Extensive analysis using molecular docking analysis, protein-protein patch docking, interface property and SASA analysis testifies superior inhibitory potential of Nutlin 3A akin compound; however the in vitro and in vivo experimental correlates are required to complement our observations.

\section{References}

Ahmad S, Gromiha M, Fawareh H, Sarai A (2004). ASAView: database and tool for solvent accessibility representation in proteins. BMC bioinformatics, $\mathbf{5}, 51$.

Bandaru S, Marri VK, Kasera P, et al (2014). Structure based virtual screening of ligands to identify cysteinyl leukotriene receptor 1 antagonist. Bioinformat, 10, 652.

Basse MJ, Betzi S, Bourgeas R, et al (2013). 2P2Idb: a structural database dedicated to orthosteric modulation of proteinprotein interactions. Nucleic Acids Res, 41, 824-27.

Chen J, Marechal V, Levine AJ (1993). Mapping of the p53 and mdm-2 interaction domains. Mol Cell Biol, 13, 4107-14.

Cheng F, Li W, Zhou Y, et al (2012). admetSAR: a comprehensive source and free tool for assessment of chemical ADMET properties. J Chem Inf Model, 52, 3099-105.

DeLeo AB, Jay G, Appella E, Dubois GC, et al (1979). Detection of a transformation-related antigen in chemically induced sarcomas and other transformed cells of the mouse. Proc Natl Acad Sci U S A, 76, 2420-4.

Feki A, Irminger-Finger I (2004). Mutational spectrum of p53 mutations in primary breast and ovarian tumors. Crit Rev Oncol Hematol, 52, 103-16.

Freedman DA, Levine AJ (1998). Nuclear export is required for degradation of endogenous $\mathrm{p} 53$ by MDM2 and human papillomavirus E6. Mol Cell Biol, 18, 7288-93.

Fridman JS, Lowe SW (2003). Control of apoptosis by p53. Oncogene, 22, 9030-40.

Haupt Y, Maya R, Kazaz A, Oren M (1997). MDM2 promotes the rapid degradation of p53. Nature, 387, 296-9.

Lane DP, Crawford LV (1979). T antigen is bound to a host protein in SV40-transformed cells. Nature, 278, 261-3.

Linzer DI, Levine AJ (1979). Characterization of a 54K dalton cellular SV40 tumor antigen present in SV40-transformed cells and uninfected embryonal carcinoma cells. Cell, 17, 43-52.

Liu J, Zheng Y, Lei D, et al (2011). MDM2 309T> G polymorphism and risk of squamous cell carcinomas of head and neck: a meta-analysis. Asian Pac J Cancer Prev, 12, 1899-03.

Maunz A, Gütlein M, Rautenberg M, et al (2013). Lazar: a modular predictive toxicology framework. Front Pharmacol, 4, 38.

Momand J, Jung D, Wilczynski S, Niland J (1998). The MDM2 gene amplification database. Nucleic Acids Res, 26, 3453-9.

Momand J, Zambetti GP, Olson DC, George D, Levine AJ (1992). The mdm-2 oncogene product forms a complex with the $\mathrm{p} 53$ protein and inhibits $\mathrm{p} 53$ - mediated transactivation. Cell, 69, 1237-45.

Nelder JA, Mead R (1965). A simplex method for function minimization. Comput J, 7, 308-13.

Oliner JD, Kinzler KW, Meltzer PS, et al (1992). Amplification of a gene encoding a 53 -associated protein in human sarcomas. Nature, 358, 80-3.

Patton JT, Mayo LD, Singhi AD, et al (2006). Levels of HdmX expression dictate the sensitivity of normal and transformed cells to Nutlin- 3. Cancer Res, 66, 3169-76.

Ray-Coquard I, Blay JY, Italiano A, et al (2012). Effect of the MDM2 antagonist RG7112 on the P53 pathway in patients with MDM2-amplified, well-differentiated or dedifferentiated liposarcoma: an exploratory proof-ofmechanism study. Lancet Oncol, 13, 1133-40.

Reichmann D, Phillip Y, Carmi A, Schreiber G (2008). On the contribution of water-mediated interactions to protein- 

complex stability. Biochem, 47, 1051-60.

Sarek G, Kurki S, Enback J, et al (2007). Reactivation of the p53 pathway as a treatment modality for KSHVinduced lymphomas. J Clin Invest, 117, 1019-28.

Schneidman-Duhovny D, Inbar Y, Nussinov R, Wolfson HJ (2005). PatchDock and SymmDock: servers for rigid and symmetric docking. Nucleic Acids Res, 33, 363-67.

Shangary S, Qin D, McEachern D, et al (2008). Temporal activation of $\mathrm{p} 53$ by a specific MDM2 inhibitor is selectively toxic to tumors and leads to complete tumor growth inhibition. Proc Natl Acad Sci USA, 105, 3933-8.

Srivatanakul P, Sriplung H (2004). Epidemiology of liver cancer: an overview. Asian Pac J Cancer Prev, 5, 118-25

Stakleff KS, Sloan T, Blanco D, et al (2012). Resveratrol exerts differential effects in vitro and in vivo against ovarian cancer cells. Asian Pac J Cancer Prev, 13, 1333-40.

Teodoro JG, Evans SK, GreenMR (2007). Inhibition of tumor angiogenesis by p53: a new role for the guardian of the genome. J Mol Med, 85, 1175-86.

Thomsen R, Christensen MH (2006). MolDock: a new technique for high-accuracy molecular docking. J Med Chem, 49, 3315-21.

Chanda Sinha, Anuradha Nischal, Srinivas Bandaru, et al (2015). An In silico Approach for Identification of Novel Inhibitors as a Potential Therapeutics Targeting HIV-1 Viral Infectivity Factor. Current Topics Med Chem, 15, 65-72.

Tian, X, Tian Y, Ma P, et al (2013). Association between MDM2 SNP309 T>G and risk of gastric cancer: a meta-analysis. Asian Pac J Cancer Prev, 14, 1925-9.

Tovar C, Rosinski J, Filipovic Z, et al (2006). Small-molecule MDM2 antagonists reveal aberrant p53 signaling in cancer: implications for therapy. Proc Natl Acad Sci U S A, 103, 1888-93.

Vassilev LT, Vu BT, Graves B, et al (2004). In vivo activation of the 553 pathway by small molecule antagonists of MDM2. Science, 303, 844-8.

Vassilev LT,Vu BT,Graves B, et al (2004). In vivo activation of the p53 pathway by small-molecule antagonists of MDM2. Science, 303, 844- 8 .

Vousden KH, Lu X (2002). Live or let die: the cell's response to p53. Nat Rev Cancer, 2, 594-604.

Wu X, Bayle JH, Olson D, Levine AJ (1993). The p53-mdm-2 autoregulatory feedback loop. Genes Dev, 7, 1126-32.

Xu T, Xu ZC, Zou Q, Yu B et al (2012). P53 Arg72Pro polymorphism and bladder cancer risk--meta-analysis evidence for a link in Asians but not Caucasians. Asian Pac J Cancer Prev, 13, 2349-54.

Yang JM, Chen CC (2004). Gemdock: A generic evolutionary method for molecular docking. Proteins, 55, 288-304.

Yang ZH, Zhou CL, Zhu H et al (2014). A functional SNP in the MDM2 promoter mediates E2F1 affinity to modulate cyclin D1 expression in tumor cell proliferation. Asian Pac J Cancer Prev, 15, 3817. 